\title{
Use of quantitative real-time PCR for studying the dissemination of Leptospira interrogans in the guinea pig infection model of leptospirosis
}

\author{
Kristel Lourdault, Florence Aviat and Mathieu Picardeau \\ Institut Pasteur, Unité de Biologie des Spirochètes, Paris, France
}

Correspondence

Mathieu Picardeau

mathieu.picardeau@pasteur.fr

Received 22 November 2008

Accepted 14 January 2009

\begin{abstract}
The dynamics of leptospirosis infection have been poorly studied. The purpose of this study was to determine the $\mathrm{LD}_{50}$, rate of bacterial dissemination, histopathology and antibody responses against leptospira following inoculation with the highly virulent Leptospira interrogans Fiocruz L1130 strain in a guinea pig model of leptospirosis. Three routes of infection (intraperitoneal, conjunctival and subcutaneous inoculation) were used to establish disease in guinea pigs. The size and kinetics of leptospiral burdens in the blood and tissues of infected animals were determined over a 1 week course of infection using quantitative real-time PCR (qPCR). Bacteraemia peaked at day 5 post-infection reaching more than $5 \times 10^{4}$ leptospires $\mathrm{ml}^{-1}$. The highest spirochaetal load was found in the liver and kidneys, and was associated with alterations in organ tissues and a decline in liver and kidney functions. In contrast, lesions and bacteria were not detected in guinea pigs infected with an avirulent strain derived from a high-passage-number in vitro-passaged variant of the Fiocruz L1-130 strain. The use of qPCR supports the findings of earlier studies and provides an easy and reliable method for the quantification of $L$. interrogans in the tissues of infected animals. qPCR will be used in future studies to evaluate the efficacy of vaccine candidates against leptospirosis and the virulence of selected $L$. interrogans mutants relative to the parental strain.
\end{abstract}

\section{INTRODUCTION}

Spirochaetes, which include the medically important pathogens that cause Lyme disease, syphilis and leptospirosis, constitute an evolutionarily unique group of bacteria. Leptospirosis, which is considered the most geographically widespread zoonosis, has emerged as a major public health problem in developing countries (Bharti et al., 2003; Levett, 2001; McBride et al., 2005). Water contaminated by urine from animal reservoirs is the main source of human infection, usually through cut or abraded skin. More than 500000 cases of severe leptospirosis occur each year, with a mortality rate of 5-20\% (WHO, 1999).

Leptospires are highly motile bacteria that are able to penetrate skin and mucous membranes, and rapidly disseminate to other tissues shortly after infection. In susceptible hosts such as humans, systemic infection can produce severe multi-organ manifestations, including jaundice, acute renal failure and severe haemorrhage in the lungs and other organs. However, in animal reservoirs such as the domestic rat, infection produces chronic and

Abbreviations: c.j., conjunctival; i.p., intraperitoneal; p.i., post-infection; qPCR, quantitative real-time PCR; s.c., subcutaneous; WHO, World Health Organization. persistent asymptomatic carriage in the renal tubules (Bharti et al., 2003; Levett, 2001; McBride et al., 2005).

The use of experimental models of leptospirosis remains a critical component for elucidating disease pathogenesis. Although mice are usually not susceptible to leptospirosis, reports have described lethal infections in young $\mathrm{C} 3 \mathrm{H} / \mathrm{HeJ}$ mice, which carry a mutation inactivating the trl4 gene (Nally et al., 2005; Pereira et al., 1998), and also in cyclophosphamide-treated mice (Masuzawa et al., 1991). Like rats, the common domestic mouse is an asymptomatic carrier of pathogenic leptospires. Most studies exploring the pathogenicity of Leptospira have therefore used hamsters or guinea pigs as animal models. In these species, infection with virulent Leptospira causes a fatal acute disease similar to severe human disease (Bharti et al., 2003; Levett, 2001; McBride et al., 2005). Other animals have been used for modelling leptospirosis, including gerbils (Sonrier et al., 2000; Yukawa et al., 1990) and marmoset monkeys (Pereira et al., 2005).

Half a century ago, Faine (1957a, b) studied the dissemination of Leptospira interrogans in infected guinea pigs by dark-field microscopy. In the present study, we used quantitative real-time PCR (qPCR) to evaluate the dissemination of $L$. interrogans in a guinea pig model of 
leptospirosis. Our results indicate that $\mathrm{qPCR}$ provides an accurate method for comparing the virulence of leptospires and will help in the design of further infection experiments.

\section{METHODS}

L. interrogans strains. L. interrogans serovar Copenhageni strain Fiocruz L1-130 was originally a clinical isolate obtained from a leptospirosis outbreak in Salvador, Brazil (Ko et al., 1999), the genome of which was sequenced (Nascimento et al., 2004). An avirulent strain [i.e. intraperitoneal (i.p.) injection of $10^{8}$ bacteria does not kill guinea pigs or hamsters], called strain Fiocruz P53 (kindly provided by Albert Ko, Centro de Pesquisas Gonçalo Moniz, Fundação Oswaldo Cruz, Salvador, Brazil), derived from the Fiocruz L1-130 strain, was also used in this study. Strains were grown at $30{ }^{\circ} \mathrm{C}$ in EMJH (Ellinghausen \& McCullough, 1965; Johnson \& Harris, 1967) liquid medium.

Infection of guinea pigs. Hartley male guinea pigs (Charles River Laboratories) were obtained at 3 weeks of age (weight 150-200 g). Before infection, bacteria were filtered through $0.8 \mu \mathrm{m}$ pores to remove bacterial aggregates, counted in a Petroff-Hauser chamber and resuspended at the appropriate concentration. Guinea pigs were i.p. inoculated with $1 \mathrm{ml}$ of different doses of virulent and avirulent strains of L. interrogans. For conjunctival (c.j.) injection, guinea pigs were anaesthetized by an intramuscular injection of $20 \mathrm{mg}$ ketamine $\mathrm{kg}^{-1}$ and $0.15 \mathrm{mg}$ xylazine $\mathrm{kg}^{-1}$. The inoculum for subcutaneous (s.c.) and c.j. (ocular drop of a bacterial suspension) injection was prepared in 500 and $10 \mu \mathrm{l}$, respectively. Animals were monitored daily for clinical signs of leptospirosis (prostration and jaundice) and survival. Surviving animals were sacrificed at 21 days post-challenge. The $\mathrm{LD}_{50}$ for L. interrogans serovar Copenhageni strain Fiocruz L1130 in 3-week-old guinea pigs was estimated according to the method of Reed \& Muench (1938), with groups of four guinea pigs with inocula of $10^{0}$ to $10^{8}$ leptospires followed for 21 days. Protocols for animal experiments were prepared according to the guidelines of the Animal Care and Use Committees of the Institut Pasteur.

Collection of blood and tissues and DNA extraction. Blood was collected by cardiac puncture of anaesthetized guinea pigs (see above). Sera were collected by centrifugation at $1000 \mathrm{~g}$ for $15 \mathrm{~min}$ at room temperature and kept frozen $\left(-20{ }^{\circ} \mathrm{C}\right)$ until analysis. Serum samples were used to determine the levels of aspartate aminotransferase, bilirubin, urea, creatinine and alkaline phosphatase. Total genomic DNA was also extracted using a blood DNA purification kit (Maxwell; Promega). To collect tissues at each time point, the guinea pigs were euthanized by asphyxiation with $\mathrm{CO}_{2}$. The abdominal cavity was opened aseptically and the spleen, liver, lungs, kidneys, heart and adrenal glands were removed. The skull was also opened and the brain was removed aseptically. The tissues were then homogenized (Ultra Turrax homogenizer) and diluted in sterile water, and total genomic DNA was extracted from $100 \mu \mathrm{l}$ organ homogenates, which corresponded to approximately $20 \mathrm{mg}$ organ tissue, using a tissue DNA purification kit (Maxwell; Promega). The concentration of DNA obtained from tissues was determined spectrophotometrically by absorbance at $260 / 280 \mathrm{~nm}$.

Histopathology. At the time of necropsy, the brain, liver, lungs, kidneys, spleen, heart and adrenal glands were removed and fixed in $10 \%$ buffered formaldehyde. The samples were cut into thin sections, mounted on glass slides and processed for haematoxylin and eosin staining, Warthin-Starry silver impregnation and immunohistochemistry with antiserum specific to the major leptospiral outer membrane lipoprotein, LipL32 (Ristow et al., 2007). A pathologist viewed the histopathological preparations without knowing the infection status of the animals.

ELISA. L. interrogans was grown in EMJH until the culture reached an $\mathrm{OD}_{420}$ of 0.3 . Concentrations were adjusted to $10^{9}$ bacteria $\mathrm{ml}^{-1}$ in

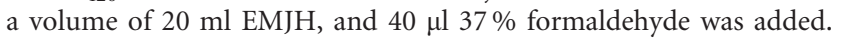
Bacterial suspensions were incubated for $2 \mathrm{~h}$ at room temperature and then boiled for $1.5 \mathrm{~h}$. After adjusting the $\mathrm{pH}$ to 9.6, 96-well flatbottomed polystyrene assay plates were coated overnight at $4{ }^{\circ} \mathrm{C}$ with $100 \mu \mathrm{l}$ whole-cell bacterial antigen. The plates were washed three times with $0.2 \%$ Tween 20 in PBS (PBST), incubated with $100 \mu \mathrm{l}$ blocking solution (SeaBlock; Interchim) diluted $1: 2$ in TNE buffer [150 mM NaCl, $50 \mathrm{mM}$ Tris/ $\mathrm{HCl}(\mathrm{pH} 7.4), 0.8 \mathrm{mM}$ EDTA] at $37{ }^{\circ} \mathrm{C}$ for $1 \mathrm{~h}$ and then washed again in PBST. Duplicate $100 \mu \mathrm{l}$ serial dilutions of the sera in TNE buffer $(1: 50$ to $1: 400)$, including positive and negative controls, were incubated for $1 \mathrm{~h}$ at $37^{\circ} \mathrm{C}$. The plates were washed three times with PBST and $100 \mu \mathrm{l} 6000$ - or 7000fold dilutions of goat anti-guinea pig IgM (Nordic Immunology) or IgG (Jackson Immunoresearch) conjugated to horseradish peroxidase, respectively, was added to each well. The plates were incubated for $1 \mathrm{~h}$ at $37^{\circ} \mathrm{C}$. After washing, $100 \mu \mathrm{l}$ substrate buffer $(0.5 \mathrm{mM} \mathrm{2-2'-}$ azinodiethylbenz-thiazoline-6-sulphonic acid, $10 \mathrm{mM}$ citric acid, $0.03 \%$ hydrogen peroxide, $\mathrm{pH} 4.5$ ) was added to each well. Plates were incubated in the dark at $37^{\circ} \mathrm{C}$ for $30 \mathrm{~min}$. Absorbance was measured using an ELISA reader (model 680; Bio-Rad) at $405 \mathrm{~nm}$.

qPCR. The concentration of leptospires in animal tissue was quantified by qPCR using a LightCycler system (Roche). All reactions were performed with LightCycler FastStart DNA master SYBR Green I (Roche Applied Science) using a $20 \mu \mathrm{l}$ volume in each reaction capillary. The 330 bp 16S rRNA gene amplicons of Leptospira were quantified using the primers LA (5'-GGCGGCGCGTCTTAAACATG$\left.3^{\prime}\right)$ and LB (5'-TTCCCCCCATTGAGCAAGATT-3') (Mérien et al., 1992). PCR conditions were as follows (ramp rates of $20{ }^{\circ} \mathrm{C} \mathrm{s}^{-1}$ ): initial denaturation $95{ }^{\circ} \mathrm{C}$ for $600 \mathrm{~s}$, followed by 45 cycles of amplification $95{ }^{\circ} \mathrm{C}$ for $10 \mathrm{~s}, 57^{\circ} \mathrm{C}$ for $8 \mathrm{~s}$ and $72{ }^{\circ} \mathrm{C}$ for $10 \mathrm{~s}$, and fusion at $95{ }^{\circ} \mathrm{C}$ for $360 \mathrm{~s}$. Results were expressed as the number of Leptospira detected in $1 \mu \mathrm{g}$ tissue DNA or in $1 \mu \mathrm{l}$ serum. A standard curve with DNA extracted from 10-fold dilutions of known numbers of leptospires was used for quantification. Results were systematically normalized to the guinea pig housekeeping gene glyceraldehyde-3phosphate dehydrogenase (GAPDH) (forward 5'-AATGGGAAGCTCACAGGTATGG-3', and reverse 5'-ATGTCATCGTATTTGGCCGGT-3'; Bourne et al., 2005) in order to correct variations in nucleic acid quality and quantity. For each organ, DNA was extracted from two samples of homogenized organ and GPCR was performed in duplicate for each DNA extract, generating four values per organ. Similarly, four values were generated for each blood sample. Four guinea pigs were used for each time point in each group.

\section{RESULTS}

\section{$L_{50}$ values for guinea pigs infected by three different inoculation routes}

We initially evaluated the $\mathrm{LD}_{50}$ values of the Fiocruz strain in 3-week-old guinea pigs using three different inoculation routes for suitability as a model of leptospirosis. The i.p. inoculation route is the most commonly used in standard experimental models for leptospirosis. It produces a lethal infection in guinea pigs and mimics the clinical presentation of severe leptospirosis in humans. However, this route of infection may not reflect conditions encountered during natural infection, as leptospires enter the host by 
penetrating breaks in the skin or traversing the mucosal membranes. We therefore also evaluated c.j. and s.c. challenge routes in guinea pigs. Strain Fiocruz L1-130 had $\mathrm{LD}_{50}$ values of 133,251 and $2 \times 10^{5}$ leptospires after i.p., s.c. and c.j. inoculations, respectively. By the three routes of infection, strain Fiocruz produced lethal infection with inocula of $10^{7}$ bacteria in all guinea pigs tested. By using this high inoculum, animals experimentally infected by i.p. and s.c. injections died between 6 and 7 days post-infection (p.i.), whilst c.j. caused death in guinea pigs at 7-9 days p.i. We therefore chose an inoculum of $10^{7}$ leptospires for our study and followed the course of infection over the first 6 days p.i.

\section{Characterization of the guinea pig model of infection}

The quantitative detection of L. interrogans, in combination with a host gene, by qPCR can be used to compare the bacterial burdens of different samples. In a preliminary experiment, tissue (kidneys, liver and lungs) or serum specimens were mixed with serial dilutions of known copy numbers of leptospires and DNA was isolated from this mixture. qPCR showed that host cells did not inhibit the amplification of $L$. interrogans DNA, even when host cells were present in a large excess over spirochaetes (data not shown).

Guinea pigs were i.p. infected with $10^{7}$ virulent leptospires. Blood and tissues were then collected to assess the bacterial burden by qPCR. Bacteraemia peaked between 4 and 6 days p.i., with approximately $10^{5}$ leptospires $\mathrm{ml}^{-1}$ at 4 days p.i. and a bacteraemia ranging from $6.5 \times 10^{4}$ to $1.2 \times 10^{6}$ leptospires $\mathrm{ml}^{-1}$ at 5 days p.i. (Fig. 1). For a single guinea pig, a decrease in bacterial number was noted

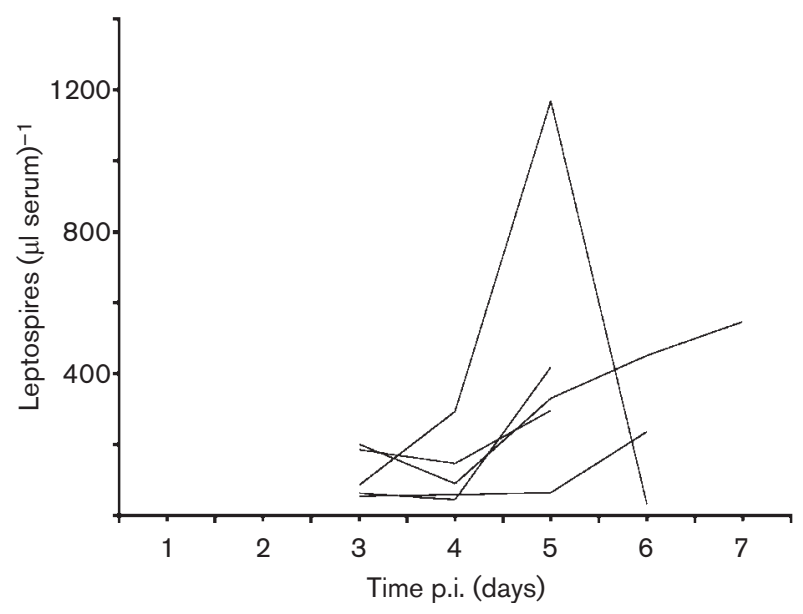

Fig. 1. Quantification of $L$. interrogans in the blood of infected guinea pigs. Bacteraemia was followed by qPCR in guinea pigs i.p. injected with $10^{7}$ leptospires. Blood samples were taken every day for up to 7 days. Each line represents the results of one animal. when compared with the other four guinea pigs at 6 days p.i. Guinea pigs were sacrificed every day and the severity of infection was quantified by qPCR amplification of DNA from samples from the lungs, spleen and liver. Whole organs were homogenized before DNA extraction to avoid potential variations in spirochaetal load within an organ. As an internal control, and to normalize the amount of template DNA, the GAPDH gene was also amplified. Greater numbers of leptospires were recovered from the liver and kidneys of guinea pigs at 4-6 days after challenge (Fig. 2). Bacteria multiplied in the liver, kidneys and lungs between 5 and 6 days p.i., increasing in number by $1-2$ logs and reaching $7.5 \times 10^{4}, 3.45 \times 10^{4}$ and $1.25 \times 10^{4}$ leptospires $(1 \mu \mathrm{g}$ tissue DNA $)^{-1}$ in the livers, kidneys and lungs, respectively (Fig. 2). We also recovered L. interrogans from the spleen, heart and adrenal glands of guinea pigs at 6 days after infection (Fig. 3). Leptospires were not detected in significant numbers in any of the brains examined from infected guinea pigs (4/4 animals had threshold cycle values $>30$ ).

The most striking features at the necropsy of infected guinea pigs were s.c. jaundice and haemorrhage of the lungs. The kidneys were pale and swollen, the liver was yellowish and the spleen was enlarged to twice the normal size. Haematoxylin and eosin staining of sectioned lungs, kidney, spleen and liver from infected guinea pigs demonstrated characteristic histopathological findings for leptospirosis, i.e. hepatic necrosis, acute renal tubular necrosis and lung haemorrhages. None of these features was observed in healthy control animals (data not shown). Leptospira could be identified by silver staining as filamentous thread-like structures in the lumen of tubules in the kidney sections and were closely associated with liver cells, and were also found in the lungs (Fig. 3b). Leptospires were also detected in the spleen and adrenal glands by immunohistochemistry (Fig. 3b).

Infected guinea pigs exhibited normal levels of aspartate aminotransferase, bilirubin, urea, creatinine and alkaline phosphatase in the first 5 days p.i. compared with noninfected animals (Fig. 4). On days 6 and 7, the kidney functions of infected guinea pigs exhibited elevated levels of urea and creatinine compared with uninfected controls. Infected guinea pigs also showed hyperbilirubinaemia, and an increase in aspartate aminotransferase and alkaline phosphatase activities (Fig. 4). These results were consistent with the severe liver and kidney deterioration observed by histopathology (Fig. 3b).

An IgM- and IgG-specific ELISA was used to measure the antibody response stimulated in guinea pigs by i.p. inoculation with $L$. interrogans. A substantial anti-leptospiral $\operatorname{IgG} / \operatorname{IgM}$ response was observed at 56 days p.i. in infected animals (Fig. 5).

Two other routes of infection have also been reported for establishing disease in guinea pigs. When guinea pigs were infected with the virulent strain by s.c. and c.j. injections, we initially observed low levels of bacterial growth in the 


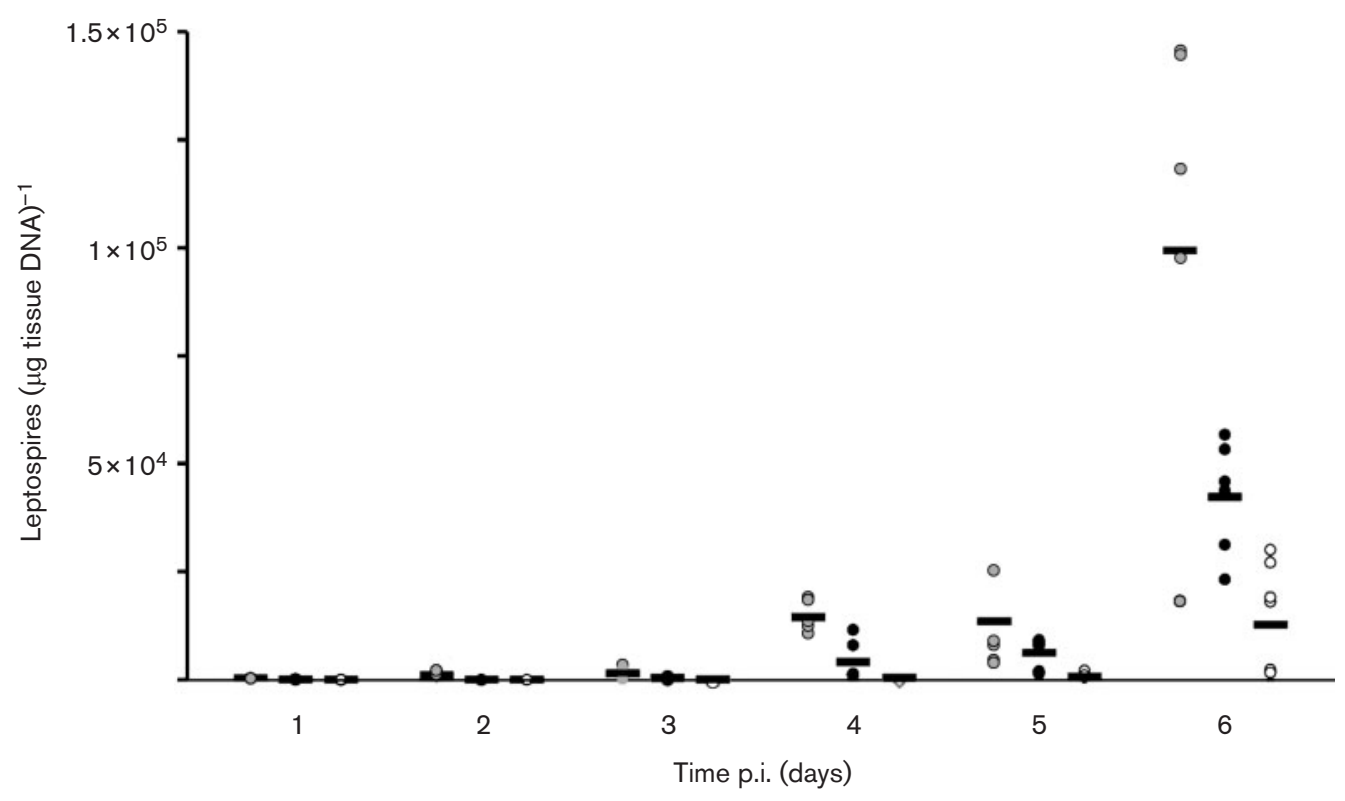

Fig. 2. Time course of the number of leptospires in various organs taken from guinea pigs i.p. inoculated with $L$. interrogans. The number of leptospires ( $\mu \mathrm{g}$ tissue DNA) ${ }^{-1}$, as determined by qPCR, is shown for liver (grey circles), kidneys (black circles) and lungs (white circles). Horizontal bars represent the median value for each time point.

bloodstream at 3 days p.i. $\left[<10^{3}\right.$ leptospires $\left.(\mathrm{ml} \text { serum })^{-1}\right]$ and few or no bacteria were detected in the liver, kidneys and lungs. However, between 4 and 6 days p.i., there was tremendous outgrowth of bacteria in the bloodstream, with numbers of organisms reaching $>10^{5}$ leptospires $\mathrm{ml}^{-1}$. The period of heavy colonization of the liver, lungs and kidneys was detected at 6-7 days p.i. (compared with 46 days p.i. in the i.p.-inoculated guinea pigs), with bacterial burdens reaching $6 \times 10^{4}$ and $4.25 \times 10^{4}$ leptospires $(1 \mu \mathrm{g}$ tissue DNA) $)^{-1}$ in the liver and kidneys, respectively (data not shown). Guinea pigs developed similar physical signs and pathology after i.p., s.c. and c.j. inoculation with $L$. interrogans (data not shown). In conclusion, the course of dissemination of $L$. interrogans in s.c.- and c.j.-infected guinea pigs was similar to the course reported by i.p. inoculation.

\section{Infection with an avirulent strain}

A Fiocruz strain that had lost its virulence phenotype following prolonged in vitro culture was also used in our study. The bacterial burdens in the blood, lungs, liver and kidneys of guinea pigs i.p. infected with the virulent and avirulent strains were quantitatively compared. All samples from guinea pigs infected with the avirulent strain were negative by qPCR. These results are consistent with the absence of spirochaetes by histopathology and the lack of evidence of any liver or kidney alterations by the analysis of blood parameters (data not shown). No IgG and IgM antibody responses against leptospira were detected by ELISA (Fig. 5).

\section{DISCUSSION}

Although PCR techniques have been used to detect pathogenic leptospires in patients and infected animals (Roczek et al., 2008; Segura et al., 2005; Smythe et al., 2002; Truccolo et al., 2002; Viriyakosol et al., 2006), until now relatively little has been known about the size and kinetics of leptospiral burdens in blood and tissues. Here, we combined different approaches, including qPCR, to gain a better insight into leptospiral disease pathophysiology. We showed that infection with the strain Fiocruz L1-130, using three routes of infection, produced a lethal infection in guinea pigs that mimicked the clinical presentation of severe leptospirosis in patients, as described elsewhere (Faine, 1957a, b; Van den Ingh \& Hartman, 1986; Yang et al., 2006). The estimated i.p. and s.c. $\mathrm{LD}_{50}$ values in our studies were consistent with those reported by Silva et al. (2008) using i.p. injection in 9-week-old hamsters (Silva et al., 2008).

Our qPCR results indicated that the leptospiral bacteraemia was at a low level during the first 3 days of infection, with a mean value of $10^{4}$ leptospires $\mathrm{ml}^{-1}$, before reaching a peak of more than $10^{6}$ leptospires $\mathrm{ml}^{-1}$ at 5 days p.i. In humans, it has been shown that a density of $10^{4}$ leptospires $\mathrm{ml}^{-1}$ is a critical threshold for the vital prognosis of patients (Segura et al., 2005; Truccolo et al., 2001). Following the same animal allowed us to estimate the bacterial density in the blood during the course of the disease. Our data indicated that leptospires grow exponentially, with a doubling time of approximately $10 \mathrm{~h}$ in the bloodstream, in comparison with $20 \mathrm{~h}$ in EMJH liquid 

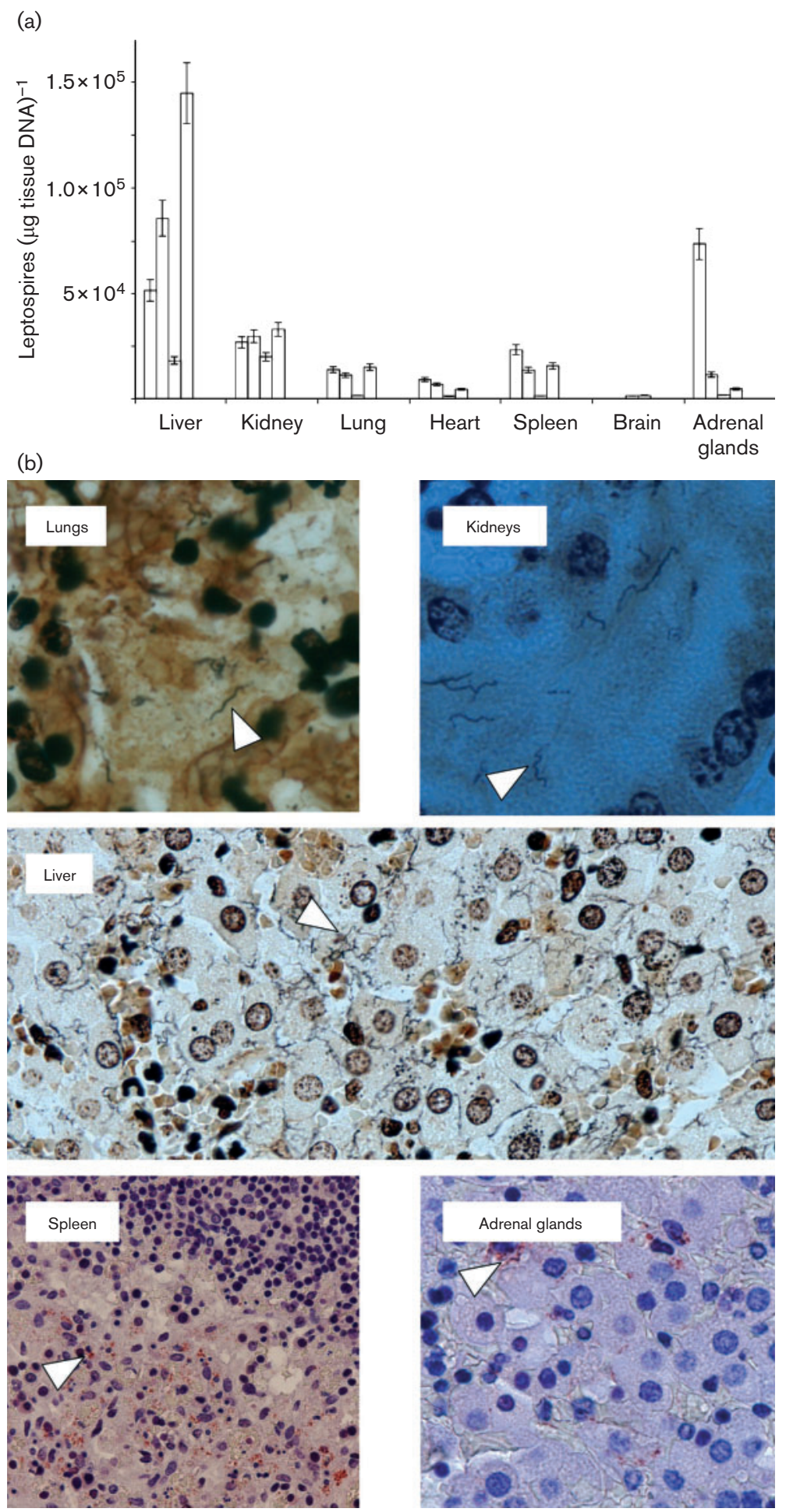

Fig. 3. Bacterial burden in various tissues of guinea pigs with severe leptospirosis. (a) Recovery of $L$. interrogans from the lungs, kidneys, spleen, brain, heart, adrenal glands and liver of infected animals. Guinea pigs were i.p. inoculated with $10^{7}$ leptospires and sacrificed at 6 days p.i. The bacterial burden was measured by qPCR. Each bar represents the bacterial burden for one animal. (b) Visualization of leptospires (indicated by arrowheads) in the liver, kidneys, lungs, spleen and adrenal glands of guinea pigs infected with $L$. interrogans. All images are from guinea pigs at 6 days p.i. Tissues were stained by Warthin-Starry silver impregnation (lungs, liver and kidneys) or by immunohistochemistry with antiserum specific to LipL32 (adrenal glands and spleen). Magnification $\times 400$. medium (unpublished data). This is in agreement with the mean of $8 \mathrm{~h}$ found by Faine (1957b) by dark-field microscopy in tissues of infected guinea pigs. The focus of our study was the liver, kidneys and lungs, as prior studies have shown that they have the highest spirochaetal load of any tissue examined in animals inoculated with $L$. interrogans. In infected guinea pigs, there was a rapid flood of leptospira from the bloodstream to the liver, which is a systemic tissue, and to a lesser extent to the kidneys and lungs. Bacterial load progressively increased in liver, kidneys and lungs in guinea pigs from 5 to 6 days p.i. The high bacterial load measured at 6 days p.i. in guinea pigs, just before the onset of death, was associated with tissue pathologies and marked alterations of liver and 


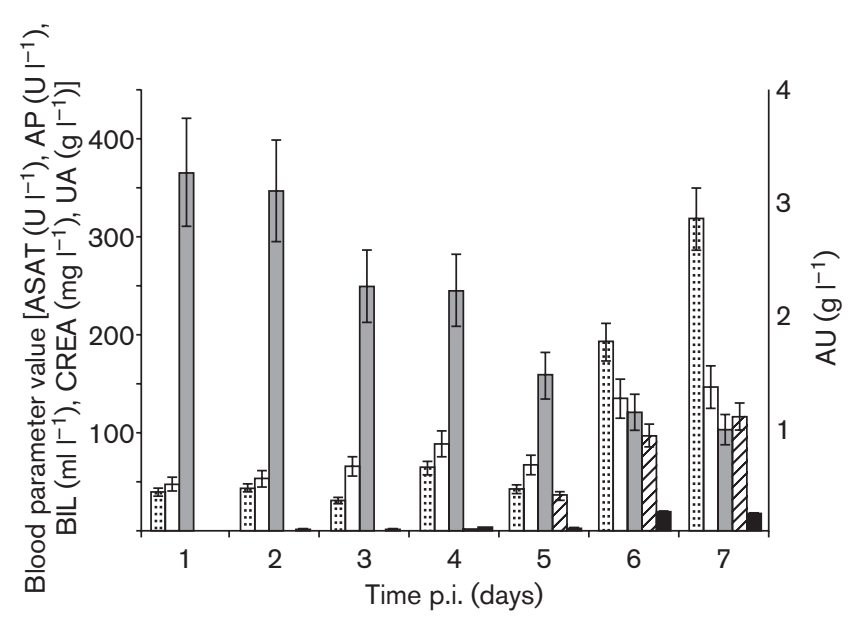

Fig. 4. Time course of various blood parameters of guinea pigs infected with $L$. interrogans. Serum from guinea pigs inoculated with $10^{7}$ leptospires was analysed for levels of aspartate aminotransferase (ASAT) (white bars), bilirubin (BIL) (hatched bars), urea (UA) (spotted bars), creatinine (CREA) (black bars) and alkaline phosphatase (AP) (grey bars). Each column represents the mean \pm SD from three guinea pigs. For four uninfected controls, the range for UA was $0.42-0.47 \mathrm{~g}$ $\mathrm{I}^{-1}$, for ASAT was 41-57 $\mathrm{U} \mathrm{I}^{-1}$ and for AP was 257-365 $\mathrm{U} \mathrm{I}^{-1}$; there was no detectable level of CREA or BIL. kidney functions. The liver and kidneys contained the highest densities of organisms, with more than $5 \times 10^{3}$ leptospires $(1 \mu \mathrm{g} \text { tissue DNA })^{-1}$ at 6 days p.i. In a similar experimental guinea pig model, Faine (1957b) estimated that the liver contained the highest load of leptospires of the tissues examined ( $80 \%$ ), followed by the kidneys and adrenal glands. In contrast, few leptospires were recovered in the lungs, which is consistent with the relatively low number of bacteria found in the lungs by histopathology. Leptospires were also detected in the heart, adrenal glands and spleen, and could be visualized in these organs by light microscopy after appropriate staining. Although leptospires have been detected in the cerebellum and cerebrospinal fluid in patients with leptospirosis (Brown et al., 2003;

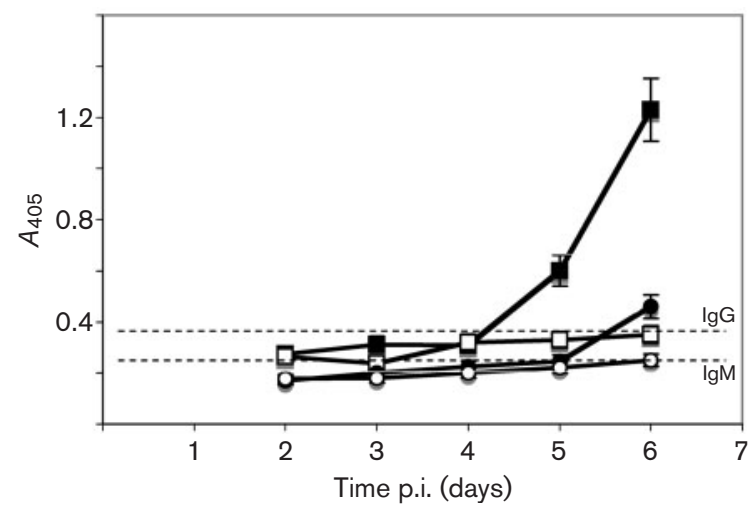

Fig. 5. Time course of $\lg G$ and $\lg M$ levels in the serum of infected guinea pigs. These are the results of ELISAs with total bacterial antigens and serum samples (diluted $1: 100$ ) from guinea pigs that were i.p. infected with $10^{7}$ leptospires. The $\lg G$ and IgM cut-off absorbance values of the serum samples from non-infected control animals are shown as dashed lines. $\mathbf{\square}$ and $\boldsymbol{\bullet}, \lg \mathbf{G}$ and $\lg M$ levels for serum samples from guinea pigs infected with the virulent strain, respectively; $\square$ and $\bigcirc, \lg G$ and $\lg M$ results for serum samples from guinea pigs infected with the avirulent strain, respectively.
Romero et al., 1998), qPCR failed to detect significant number of leptospires in the brain samples collected from guinea pigs at 6 days p.i. A prolonged period of infection may be necessary for invasion of leptospires into the brain. Further studies will be carried out to determine the bacterial burdens in tissues, including brain, of guinea pigs with sublethal infections, at 2 and 3 weeks p.i.

Our data indicated that there were no major differences in the outcome and course of bacterial spread from i.p. and s.c. infections. However, by the c.j. route of infection, leptospires remained virulent but required a much higher dose to cause lethality. Although our data indicated that the progression of disease in c.j.- and s.c.-inoculated guinea pigs was slower (24-48 $\mathrm{h}$ delay) than the i.p. route, the bacterial burden in tissues and histopathology revealed no major differences between the three routes of infections. To minimize the rapid loss of animals due to lethal infection (death within 6-7 days of i.p. inoculation of $10^{7}$ leptospires), we also i.p. inoculated guinea pigs with $10^{3} \mathrm{~L}$. interrogans. Under these conditions, we could clearly differentiate two phases: a septicaemic phase during the first week of infection, which reached $10^{5}$ leptospires $(\mathrm{ml}$ serum $)^{-1}$ at 5-6 days p.i. and then progressively decreased, followed by a high bacterial load in tissues $\left[>5 \times 10^{5}\right.$ leptospires $(1 \mu \mathrm{g} \text { tissue DNA })^{-1}$ in liver and kidneys] at 10-12 days p.i., just before the onset of death (data not shown).

High variability was observed in our study, which is a limitation of the model. Outbred guinea pigs may exhibit a wide range of individual variations $(20 \%$ variation in weight, host genetic factors, physiological status, etc.). In addition, we noted that, when two young males shared the same space and food, one usually carried a more severe bacterial burden than the other, suggesting that subordinate males may be more susceptible. Further experiments need to include larger numbers of animals per group to generate statistical significance.

A significant barrier to the control and prevention of leptospirosis has been the limited understanding of 
Leptospira pathogenesis, due in part to the lack of tools available for the genetic manipulation of this pathogen. This barrier is being overcome and we are currently generating a library of mutants obtained by random transposon mutagenesis in L. interrogans (Bourhy et al., 2005; Murray et al., 2008). This advance recently allowed the characterization of the first virulence factor in pathogenic Leptospira spp. (Ristow et al., 2007). In this study, we used a high in vitro passage number variant of the Fiocruz L1-130 strain, which is avirulent, to compare the size and kinetics of bacterial burdens in blood and tissues. We did not detect lesions or bacteria in guinea pigs infected with the avirulent strain. Our results are therefore indicative that the avirulent strain is cleared rapidly after injection. Further studies will focus on determining the kinetics of dissemination for various mutant and parental strains into the blood and tissues using qPCR. This will allow us to identify factors that play a role in acute disease pathogenesis and persistent colonization. The use of c.j. and s.c. routes of infection may allow the characterization of mutants that are deficient in the early steps of infection. This may also allow the characterization of growthdeficient mutants in some specific organs. Thus, transposon mutants of Mycobacterium tuberculosis that cannot synthesize or transport some complex lipids are not able to grow in lungs, but their growth in liver and spleen is unaffected (Cox et al., 1999). Finally, this real-time assay could also be used (i) to determine the efficacy of antibacterial drugs (Truccolo et al., 2002), (ii) for the assessment of protective immunity of vaccine candidates and (iii) to determine the tissue distribution of different pathogenic serotypes in this guinea pig infection model of leptospirosis.

\section{ACKNOWLEDGEMENTS}

This work was supported by the French Ministry of Research 'ANR Jeunes Chercheurs' (no. 05-JCJC- 0105-01) and the Institut Pasteur. This work is part of the doctoral thesis of K. Lourdault. We are thankful to P. Stewart for critical reading of the manuscript, M. Huerre and P. Ave for the histopathological studies, C. Werts for qPCR assays, and to E. A. Wunder and A. I. Ko for the protocol for c.j. inoculation.

\section{REFERENCES}

Bharti, A. R., Nally, J. E., Ricaldi, J. N., Matthias, M. A., Diaz, M. M., Lovett, M. A., Levett, P. N., Gilman, R. H., Willig, M. R. \& other authors (2003). Leptospirosis: a zoonotic disease of global importance. Lancet Infect Dis 3, 757-771.

Bourhy, P., Louvel, H., Saint Girons, I. \& Picardeau, M. (2005). Random insertional mutagenesis of Leptospira interrogans, the agent of leptospirosis, using a mariner transposon. J Bacteriol 187, 3255-3258.

Bourne, N., Milligan, G. N., Stanberry, L. R., Stegall, R. \& Pyles, R. B. (2005). Impact of immunization with glycoprotein D2/AS04 on herpes simplex virus type 2 shedding into the genital tract in guinea pigs that become infected. J Infect Dis 192, 2117-2123.

Brown, P. D., Carrington, D. G., Gravekamp, C., Van de Kemp, H., Edwards, C. N., Jones, S. R., Prussia, P. R., Garriques, S., Terpstra,
W. J. \& Levett, P. N. (2003). Direct detection of leptospiral material in human postmortem samples. Res Microbiol 154, 581-586.

Cox, J. S., Chen, B., McNeil, M. \& Jacobs, W. R. J. (1999). Complex lipid determines tissue-specific replication of Mycobacterium tuberculosis in mice. Nature 402, 79-83.

Ellinghausen, H. C. \& McCullough, W. G. (1965). Nutrition of Leptospira pomona and growth of 13 other serotypes: fractionation of oleic albumin complex and a medium of bovine albumin and polysorbate 80. Am J Vet Res 26, 45-51.

Faine, S. (1957a). Virulence in Leptospira. I. Reactions of guinea-pigs to experimental infections with Leptospira icterohaemorrhagiae. $\mathrm{Br} J$ Exp Pathol 38, 1-7.

Faine, S. (1957b). Virulence in Leptospira. II. The growth in vivo of virulent Leptospira icterohaemorrhagiae. Br J Exp Pathol 38, 8-14.

Johnson, R. C. \& Harris, V. G. (1967). Differentiation of pathogenic and saprophytic leptospires. J Bacteriol 94, 27-31.

Ko, A. I., Galvao Reis, M., Ribeiro Dourado, C. M., Johnson, W. D. J. \& Riley, L. W. (1999). Urban epidemic of severe leptospirosis in Brazil. Salvador Leptospirosis Study Group. Lancet 354, 820-825.

Levett, P. N. (2001). Leptospirosis. Clin Microbiol Rev 14, 296-326.

Masuzawa, T., Hashiguchi, Y., Nakamura, R., Suzuki, R., Shimizu, T., Iwamoto, Y., Morita, T. \& Yanagihara, Y. (1991). Experimental lethal infection of Leptospira interrogans in mice treated with cyclophosphamide. Can J Microbiol 37, 312-315.

McBride, A. J., Athanazio, D. A., Reis, M. G. \& Ko, A. I. (2005). Leptospirosis. Curr Opin Infect Dis 18, 376-386.

Mérien, F., Amouriaux, P., Perolat, P., Baranton, G. \& Saint Girons, I. (1992). Polymerase chain reaction for detection of Leptospira spp. in clinical samples. J Clin Microbiol 30, 2219-2224.

Murray, G. L., Morel, V., Cerqueira, G. M., Croda, J., Srikram, A., Henry, R., Ko, A. I., Dellagostin, O. A., Bulach, D. M. \& other authors (2008). Genome-wide transposon mutagenesis in pathogenic Leptospira spp. Infect Immun 77, 810-816.

Nally, J. E., Fishbein, M. C., Blanco, D. R. \& Lovett, M. A. (2005). Lethal infection of $\mathrm{C} 3 \mathrm{H} / \mathrm{HeJ}$ and $\mathrm{C} 3 \mathrm{H} / \mathrm{SCID}$ mice with an isolate of Leptospira interrogans serovar Copenhageni. Infect Immun 73, 70147017.

Nascimento, A. L., Ko, A. I., Martins, E. A., Monteiro-Vitorello, C. B., Ho, P. L., Haake, D. A., Verjovski-Almeida, S., Hartskeerl, R. A., Marques, M. V. \& other authors (2004). Comparative genomics of two Leptospira interrogans serovars reveals novel insights into physiology and pathogenesis. J Bacteriol 186, 2164-2172.

Pereira, M. M., Andrade, J., Marchevsky, R. S. \& Ribeiro dos Santos, R. (1998). Morphological characterization of lung and kidney lesions in $\mathrm{C} 3 \mathrm{H} / \mathrm{HeJ}$ mice infected with Leptospira interrogans serovar icterohaemorrhagiae: defect of $\mathrm{CD}^{+}$and $\mathrm{CD}^{+}$T-cells are prognosticators of the disease progression. Exp Toxicol Pathol 50, 191-198.

Pereira, M. M., Da Silva, J. J., Pinto, M. A., Da Silva, M. F., Machado, M. P., Lenzi, H. L. \& Marchevsky, R. S. (2005). Experimental leptospirosis in marmoset monkeys (Callithrix jacchus): a new model for studies of severe pulmonary leptospirosis. Am J Trop Med Hyg 72, 13-20.

Reed, L. J. \& Muench, H. A. (1938). Simple method of determining fifty percent endpoints. Am J Hyg 27, 494-497.

Ristow, P., Bourhy, P., Da Cruz McBride, F. W., Figueira, C. P., Huerre, M., Ave, P., Girons, I. S., Ko, A. I. \& Picardeau, M. (2007). The OmpA-like protein Loa22 is essential for leptospiral virulence. PLoS Pathog 3, e97.

Roczek, A., Forster, C., Raschel, H., Hörmansdorfer, S., Bogner, K. H., Hafner-Marx, A., Lepper, H., Dobler, G., Büttner, M. \& Sing, A. (2008). Severe course of rat bite-associated Weil's disease in a patient 
diagnosed with a new Leptospira-specific real-time quantitative LUXPCR. J Med Microbiol 57, 658-663.

Romero, E. C., Billerbeck, A. E., Lando, V. S., Camargo, E. D., Souza, C. C. \& Yasuda, P. H. (1998). Detection of Leptospira DNA in patients with aseptic meningitis by PCR. J Clin Microbiol 36, 1453-1455.

Segura, E. R., Ganoza, C. A., Campos, K., Ricaldi, J. N., Torres, S., Silva, H., Céspedes, M. J., Matthias, M. A, Swancutt, M. A. \& other authors (2005). Clinical spectrum of pulmonary involvement in leptospirosis in a region of endemicity, with quantification of leptospiral burden. Clin Infect Dis 40, 343-351.

Silva, E. F., Santos, C. S., Athanazio, D. A., Seyffert, N., Seixas, F. K., Cerqueira, G. M, Fagundes, M. O., Brod, C. S., Reis, M. G. \& other authors (2008). Characterization of virulence of Leptospira isolates in a hamster model. Vaccine 26, 3892-3896.

Smythe, L. D., Smith, I. L., Smith, G. A., Dohnt, M. F., Symonds, M. L., Barnett, L. J. \& McKay, D. B. (2002). A quantitative PCR (TaqMan) assay for pathogenic Leptospira spp. BMC Infect Dis 2, 13.

Sonrier, C., Branger, C., Michel, V., Ruvoën-Clouet, N., Ganière, J. P. \& André-Fontaine, G. (2000). Evidence of cross-protection within Leptospira interrogans in an experimental model. Vaccine 19, 86-94.

Truccolo, J., Serais, O., Merien, F. \& Perolat, P. (2001). Following the course of human leptospirosis: evidence of a critical threshold for the vital prognosis using a quantitative PCR assay. FEMS Microbiol Lett 204, 317-321.

Truccolo, J., Charavay, F., Merien, F. \& Perolat, P. (2002). Quantitative PCR assay to evaluate ampicillin, ofloxacin, and doxycycline for treatment of experimental leptospirosis. Antimicrob Agents Chemother 46, 848-853.

Van den Ingh, T. S. \& Hartman, E. G. (1986). Pathology of acute Leptospira interrogans serotype Icterohaemorrhagiae infection in the Syrian hamster. Vet Microbiol 12, 367-376.

Viriyakosol, S., Matthias, M. A., Swancutt, M. A., Kirkland, T. N. \& Vinetz, J. M. (2006). Toll-like receptor 4 protects against lethal Leptospira interrogans serovar Icterohaemorrhagiae infection and contributes to in vivo control of leptospiral burden. Infect Immun 74, 887-895.

WHO (1999). Leptospirosis worldwide, 1999. Wkly Epidemiol Rec 74, 237-242.

Yang, H. L., Jiang, X. C., Zhang, X. Y., Li, W. J., Hu, B. Y., Zhao, G. P. \& Guo, X. K. (2006). Thrombocytopenia in the experimental leptospirosis of guinea pig is not related to disseminated intravascular coagulation. BMC Infect Dis 6, 19.

Yukawa, M., Mochizuki, K. \& Imamura, S. (1990). Susceptibility of Mongolian gerbils (Meriones unguiculatus) to leptospires and the protective effect of vaccination. Vet Microbiol 24, 63-71. 